\title{
Dynamic Capabilities-Based and Environment Serving Organization-Based Concepts in Strategic Management: Are They Complementary? A Theoretical Overview
}

\section{Augustinus Oroh}

Faculty Member at Executive in Strategic Management Program, Management Department, Binus Business School Master program, Bina Nusantara University, Jakarta, Indonesia

\begin{abstract}
In the last few decades resource-based concepts have been discussed and seemingly accepted by many scholars in strategic management. Some have argued and challenged them since many companies struggle to obtain and apply the strategic tools to enhance their performance and competitiveness. Competitive advantage is moving toward a different paradigm, following dynamic competition and market turbulence. In the current era of the digital economy a company's top and general managements can be blamed for not smartly leveraging their resources and responding to their customers on time with the right offerings. Therefore, it is difficult to sustain competitive advantage. This research, using theories and a practical approach, discuss the relevance of strategic management concepts, especially Dynamic Capabilities-based, Resource-based and Environment Serving Organization-based (ESO-based) perspective in the current industrial context, as the real root of strategic management theories. This paper concludes that both Dynamic Capabilities-Based as well as Resource-Based concepts complement the ESO-based concept and therefore deserved to be explored further as a strategic formula for companies.
\end{abstract}

Corresponding Author:

Augustinus Oroh

Nicoroh@yahoo.com

Received: 30 December 2019 Accepted: 29 January 2020

Published: 6 February 2020

Publishing services provided by Knowledge E

(c) Augustinus Oroh. This article is distributed under the terms of the Creative Commons

Attribution License, which

permits unrestricted use and redistribution provided that the original author and source are credited.

Selection and Peer-review unde the responsibility of the 6 th ICOEN 2019 Conference Committee.

G OPEN ACCESS

Keywords: resource-based; dynamic-capabilities; ESO-based; competitive advantage

\section{Introduction}

In the literature of strategic management, since its inception the ESO-based concept has not been widely mentioned and included as part of the school of strategic management, particularly by the school of configurations [18], in the dynamic-capabilities approach [30] and especially by the resource-based approach [ $9,33,34,23]$. The theoretical as well as the practical fundamental questions are whether the aforementioned concepts enable companies to perform better. Every company needs to anticipate strategic products and services in order to fulfill the constantly changing needs of their markets. Companies have to have strategic options and from time to time the real business of business has shown that companies who rooted their strategies in ESO-based or environment 
driven concepts have prospered when market turbulence environment has made it really difficult for companies to perform $[10,12,13,20,21,28,35]$.

Most companies facing performance predicaments, when the situations are not conducive for them to take immediate and firm actions, prefer not to think of a "plan" but to make an instant response to the issues. Other companies who really planned and prepared activities to respond to all levels of environmental turbulence take advantage of the chaotic and dynamic situation in the business environment. A volatile and turbulent environment will create a better strategic position; these are truly strategic companies.

This paper explores and discusses whether from a strategic management theoretical perspective the concept of Dynamic Capabilities [11, 30] aligns with, and supports, the earlier Environment Serving Organization (ESO-based) concept [6, 7]. This paper opens further discussion about: whether the ESO-based concept should be considered and accepted as a theory and then accordingly cited by previous research papers in strategic management context; whether ESO-based

and Resource-based concepts are complementary; whether companies should develop their strategies, capabilities, and resources following every market turbulence level described by ESO-based concept.

Following the three aforementioned concepts toward firm performance, this paper starts by giving definitions on environments, markets, products and resources as the fundamentals of the concepts. After that it will explore the basic differences of Dynamic Capabilities-based, ESO-based, and resource-based concepts. The conclusion from these three concepts toward business performance will come at a later stage and then proposals on further research will conclude the research.

\section{Overview of Three-Based Concepts in Strategic Man- agement}

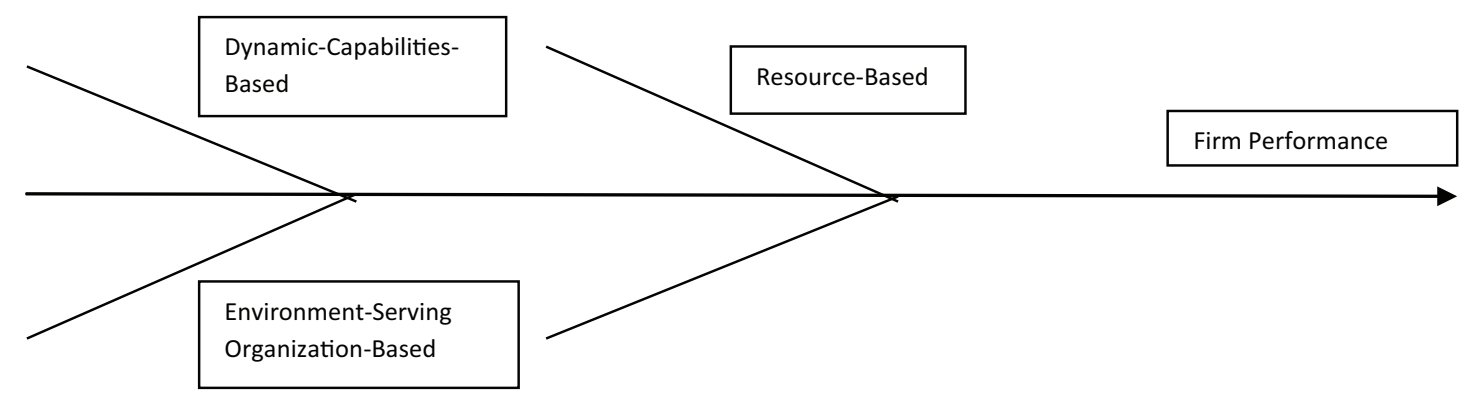




\subsection{Environment}

For the dynamic-capabilities-based, when discussing the fundamentals of the environment or market environment, it is defined as "all the dynamics that have market effects on results like prices, volumes, profits for instance the customers and competitors viewpoints, the quantity of prospective technologies used, and the momentum cost when a competitor can enter" [30]. The philosophy of market as a simple matching of supply and demand between buyer and producer has evolved significantly. There are especially technological dynamics with which producers can take advantage of their position as the technology provider to offer a better value product or service to any end user or buyer. However, in high tech industries companies will face strategic myopia if they fail to respond to product proliferation with technological substitution [4].

The Environment-Serving-Organization-based defines environmental turbulence as an external variable and then identifies the category of behavior (s) essential for success explained clearly by (at least) five distinctive turbulence levels [1, 6, 7]. Each level of market turbulence needs specific strategic actions and "resources" including capabilities and strategic behaviors [21]. In regards to firm performance, the relationship between environmental turbulence and performance are affected by a company's internal synergistic efforts, and therefore companies have to explicitly plan their activities toward synergy. Thus these companies will earn a competitive advantage.

It can be argued that the above definitions of markets and environments are fundamentally similar and very dynamic. The question is whether a company is ready to optimize its relevant resources and therefore perform when the market environment is rising, falling, or when the market is unpredictable and deteriorating the company's performance.

\subsection{Product}

The Dynamic Capabilities-based perspective defines products or "end products" as the ultimate goods and services created by the company based on employing the competences that it possesses; a company's products relative to its competitors will also depend on its competencies and will follow its capabilities [30]. Thus competencies are the "sine qua non" of company's capabilities and its performance. It is logical that best capabilities should be achieved for companies to maintain and sustain their overall performance. 
The ESO-based perspective defines products or product line of a manufacturing company as the statement of the physical characteristics of the individual products (the size, weight, materials, tolerances, etc.) which is sufficient for the purpose of setting up a manufacturing operation and the performance characteristics of the products; in regard to an aircraft manufacturing company this will include the speed, range, altitude, payload, etc. of its planes [6]. The concept of a product's mission and new matrix of market-geographic-technology was introduced and enhanced the original Ansoff matrix used by many industries and business schools until today.

\subsection{Resources}

There are two schools in strategic management today based on their analysis of resources, and they are "resource-based and "dynamic capabilities-based". The Dynamic Capabilities-based perspective defines resources as "firm-specific assets and properties that are complicated to replicate for example trade secrets, definite production properties, and also engineering know-how. These assets are complicated to transfer between entities because mainly of transactions and transfer costs, and also may contain unstated knowledge" [30].

Resource-based proponents described resources as every asset, capability, organizational internal procedure, firm characteristic, and knowledge managed by a firm that enables it to create and implement strategies that improve its competence. Furthermore it can be conveniently classified into three classes like tangible capital resources, human capital resources, and organizational capital resources [8].

Wernerfelt [33, 34] defined a resource as anything that could be considered as a strength (or weakness) of a given firm and as those tangible and intangible assets which are attached partially to the firm for instance brands, built-in know-how of technology, employment of skilled personnel, business networks, machinery, efficient internal procedures, and capital. He did not mention capabilities specifically in his definition, but we can infer implicitly from "skilled personnel and efficient internal procedures". However, this might be assumed to be similar with dynamic capabilities-based perspective as well as Barney's [8] definition.

Beside Barney and later, Peteraf's research in Resource-Based concepts [8, 9, 22, 23], Wernerfelt $(1984,1995)$ is considered one of the strongest proponents of ResourceBased view especially following his winning article (1984) on the subject, and his reevaluation a little more than a decade later (1995). His explanation on Resource-Product matrix (1984) is basically the concept of the relative importance of resources in products 
(or products to resources), and that, it is better to develop the company's resource in one market than to enter other market(s). This is to support the strategy of focusing on one market first prior to moving to other market; a company should establish itself as the "leader" first in one strategic market prior to allocating the firm's resources to another market. Problems may occur if the company is late in entering the potential market due to its rival's faster entry moves which will lessen the firm's bargaining position in the market.

TABLE 1: The Resource-Product Matrix by Wernerfelt (1984).

Resource
Market
A
B
C
D
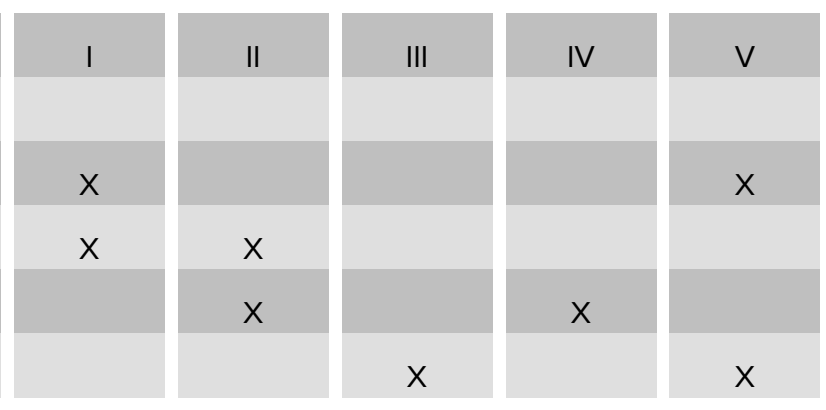

Wernerfelt conducted his analysis through a resource-product matrix, with an " $X$ " symbol indicating the importance of a resource in a product (and vice versa). By replacing the $X$ with a number (say number 1 as very important, etc.), readers can apply the relative importance of the resources in the products (or the other way around). This matrix is a similar growth-share matrix introduced by the Boston Consulting Group regardless of the weaknesses of the latter matrix. Using "1" for example for resource I in Market A, it can be implied that the specific resource will be the most valuable resource in gaining competitive advantage for the firm in a particular market which is changing over time. Most industry players face stable changes today and they ideally should have foreseen that this change and its pace will evolve faster and faster in the near future. The lifecycle of offerings will need to get shorter and shorter enabling companies to obtain competitive advantage.

It is useful to compare the Resource-Product matrix with Product-Market matrix to develop and broaden our strategic thinking in regard to establishing and maintaining a company's market(s) to maintain above average profit performance.

TABLE 2: Growth Matrix or Product-Market Matrix by Ansoff $(1965,1988)$.

\begin{tabular}{|c|c|}
\hline Product / Offering & Present \\
\hline \multicolumn{2}{|l|}{ Mission (Market) } \\
\hline Present & Market Penetration \\
\hline New & Market Development \\
\hline
\end{tabular}

New
Product Development
Diversification


Ansoff $(1965,1988)$ stated that companies who have one or more offerings (products or services) should keep in mind they are in a better position when preparing and matching their offerings with the market's needs, or where they want to establish their presence. Companies must have missions for their products, and a new mission should be sought: therefore, market research capability and advanced technology developments are key success factors (Apple's strategic position is very obvious today). Furthermore, companies have to decide which geographical area they should pursue and maintain for their current and future offerings.

In one Product-Market situation where the Product and Market already exist, a company could use Market Penetration strategy for example by lowering the price of the product, expanding distribution, and conducting heavier promotional efforts [17], where the Product already exist and the company would like to enter a New Market with that particular product, they can use Market Development by introducing existing products to different geographical areas [17], Product development involves creating new offerings for existing markets and developing new offerings, improving the offering's value to customers, or extending the offering's existing line with unique appearances like sizes, forms, and flavors. Diversification involves the development or acquisitions of offerings new to the company and the introduction of offerings not previously served by the company.

The four growth strategies should be properly executed if companies have different products and different market positions. Furthermore a company has to understand that one strategy is required at the present moment and other strategies can be executed at later stage in sequence, or sometimes together.

On the other hand, Resource-Product matrix focuses on establishing one market at a time prior to moving to other markets or opportunities (time consuming and too long) while the Product- Market matrix proposes working in several markets (because market is changing very fast, so companies need to change their offerings, including products). Those four different strategies may be due to market dynamics and therefore "maneuvering" competitors to counter its movement, or to make competitors too late to move. The Resource-Product matrix explains the importance of resources for the product existence in a particular market; the most important contribution from the "Product-Market" concept is producing strategies for companies in all market situations.

\section{The Three-Based Concepts in Strategic Management}




\subsection{Dynamic-Capabilities-based}

Scholars in strategic management have defined the dynamic capabilities concept as the firm's capability to put together internal and external know-how to deal with the speedy changing environments [30]. They refer to 'dynamic capabilities' as a method to underline developing current internal and external company competencies to focus on the constantly-moving environment, while pointing out companies like IBM, Texas Instruments, Philips, and others who appear to have followed a 'resource-based strategy' of accumulating valuable technology assets, often guarded by an aggressive intellectual property stance. However, this strategy is very often not enough to support a competitive advantage that is needed to prepare alternative strategies, or options [28].

Other proponents of the dynamic-capabilities concept included exclusive processes like product development, strategic decision making, and partnering, and defined them as explicit and particular processes [11]. They are distinctive in details and direction dependent on their appearance; they have substantial familiarities across firms (called 'best practice' and later became "routines"). Following the dynamic capabilities concept, especially on the types of dynamic markets (environment), they suggest that in a moderately dynamic market, dynamic-capabilities concept is similar to the traditional formation of routines. They are meticulous (detailed), diagnostic and logical (analytic) stable processes with obvious outcomes (level one in the ESO-based concept). On the other hand, in a high-speed market (high-velocity, level three in an ESO-based concept), they are simple, very pragmatic and unstable processes with unpredictable outcomes (a different paradigm with the ESO-based concept).

Finally, many well-known learning instruments guide the progress of dynamic capabilities. Furthermore they state that in a reasonable (moderately) dynamic markets situation, the progress emphasis is on variation while in the high-speed "high-velocit" markets, it is on selection. These are similar with the ESO-based definition on classification of the environment situation, while it is different in explaining detail capabilities needed at every turbulence level.

\subsection{Environment Serving Organization-based (ESO-based)}

Prominent scholars in strategic management described the ESO concept as the contingent strategic success formula (CSSF) which states that for a firm's best possible profitability, the levels of strategic aggressiveness and general management capability 
responsiveness of the particular firm must be aligned and matched with the environmental turbulence level. In other words a firm and especially its top management people must have capacities to adjust its strategic aggressiveness and general management capability responsiveness to the level of environmental turbulence [7].

They explained that the environment driven firms (who followed the ESO-based concept), unlike a single-minded company, would not believe that their businesses will maintain growth and stay profitable in the future and they observed the surroundings for weak and strong signals of factors like saturation of demand, replacement of current technology, changes of consumer demand, changes on social and political situations, and consistently measured the future profitability and growth in their traditional markets. The examples of Companies at that time were AT\&T, Apple and Hewlett Packard which transferred their focus from technology to the environment.

Unlike the Dynamic-Capabilities-based perspective, the ESO-based perspective described all business situation and condition succinctly into five level of environmental turbulence. Environmental turbulence is the outside unpredictable factor, focused on change, which principally identifies the category of behavior essential for success, and it is explained by five distinctive turbulence levels in the environment serving organisation-based concept. Each level requires different strategic behaviours and capabilities [7].

The business environment at level one, environmentally, is a situation of a company facing a very efficient product-market transaction, unchanging from previous condition, and smooth without any turbulence, and if there is a change, it will be very slow and therefore can be responded to relatively easy. At level two the change still remains slow but more frequent and company still can respond on time before "the shock" materializes. Many companies face this situation. At level three the change comes faster but the future is still a logical extension of the current situation, so companies can prepare for the blow.

At level four, the change is not only fast but also comes at an unexpected moment, and therefore the company must not only have a forward-looking strategy but also an environmental scanning system should be in place to prepare for strategic actions and reactions. At level five, change moves quickly and also the future is unpredictable. It is very difficult to foresee what will occur in the future. Companies should therefore be better prepared or creating a market(s), to surprise its rivals, and take advantage of the chaotic market.

Each level of environment turbulence needs different types of strategies and aggressiveness as well as essential capabilities of the top management to be responsible 
for ensuring competitive advantage. The ESO-based perspective specified that when the environment is at turbulence level one (stable and repetitive), the strategy and company's aggressiveness can be constant and steady based on previous examples or precedents. The top management capability can also be seeking stability and not in favor of changing (avoiding change). However when the turbulence is at level three with fast and incremental change, the strategies and aggressiveness need to be anticipatory and based on trend continuation (or extrapolation); the top management capability needs to be based on what the market needs and should seek for familiar change. At the extreme level turbulence of five, the environment is tumultuous and full of surprises, and change is also unpredictable. In this situation the strategies and aggressiveness need to be innovative and therefore based on creativity. The top management capability should be to create an environment, for example creating the markets with particular needs and therefore new technologies should be prepared by the company in advance to lead and stay ahead of the competition.

The researchers specifically mentioned some success stories in the business environment. Starting from the Ford Motor in the first 30 years of the twentieth century which was a production- driven company and then transitioned to a market-driven company, General Motors Corporation, a product development-driven company, converted to a research-driven company which used marketing and technology together. Environment-driven companies like Apple computers and Hewlett Packard which combined all functions together like production, marketing, product development, and advanced research.

The ESO-based concept continued by describing details of required capabilities to respond to the five environmental turbulence levels. For example the company key managers must have guardian or keeper skill when the environment level is at one, controller skills at level two, growth leader skills at level three, entrepreneur skills at level four and creation skills at level five. In regard to the culture, the top management must have a stability-seeking culture when the environment level is at one, an efficiencyseeking culture at level two, a growth-seeking culture at level three, an opportunityseeking culture at level four and an opportunity-creating culture at level five. There are more details regarding the kind of rewards to top management, problem solving skills, key management systems and key data base skills required at each level of environmental turbulence [7].

Companies who focus on ESO-based concept benefit from their rivals in wellpreparing capabilities in facing different turbulence that required different resources (including dynamic capabilities) and activities [26]. They have much better unique 
activities and well prepared skills (including entrepreneurship skills for anticipating market environment Level Four) on following the market needs and in providing more advanced offerings as well as in anticipating changes much faster than their rivals. The question is whether those are still relevant today and can take care of all market environments.

Furthermore, using Priem and Butler's argument on their strong article on the Resource-based view (2001), the Product-Market matrix concept is therefore a theory per se. The concept is not only explored in details and proven in the academic world but also very much applicable and fundamental for companies in order to sustain profits. Companies, whether they have a single business unit or many business units, need to ensure their overall competencies are ahead of their competitors regardless of whether they are the suppliers, potential entrants, buyers, or customers.

\subsection{Resource-based}

Priem and Butler (2001) cited the Resource-Based View (RBV) as mentioned by Barney (1991) in two basic arguments. A company should start with resources that are uncommon, precious and able to obtain competitive advantage. When those resources are also concurrently inimitable (difficult to be duplicated by rivals), not substitutable, and not transferable, those resources may produce a competitive advantage that is sustainable. Thus, the essential things are the scarcity as well as being precious are not enough to ensure competitive advantage, however nonimitability, nonsubstitutability, and nontransferability are important but still can not guarantee sustainability of competitive advantage.

\subsubsection{Barney (1991) presented his "RBV" model as follows:}

\begin{tabular}{|l|l|}
\cline { 2 - 2 } \multicolumn{1}{c|}{} & Value \\
\hline Firm Resource & Rareness \\
Heterogeneity & Imperfect Imitability \\
Firm Resource & -History Dependent \\
Immobility & -Causal Ambiguity \\
& -Social Complexity \\
Substitutability \\
\end{tabular}

Sustained Competitive Advantage 
From the above model Barney (1991) argued that in order for company to sustain its competitive advantage, it must have valuable resources, rareness, inimitability, and be non-substitutable (VRIN).

Complementing this resource-based concept, other scholars in resource-based concept mentioned it as "an academic construction" for understanding how competitive advantage within firms is accomplished. As it mostly focuses on the internal organization, so it is a counterpart to the conventional importance of strategy on industry structure and strategic positioning within that construction as the determinants of competitive advantage [11]. The centers of attention are the internal factor while external aspects (like environment changes) play a bigger role from time to time.

Peteraf (1993), other prominent scholar in strategic management who focused on resources, clearly defined that four conditions that must be met for a firm to enjoy above-average performance. Those are: using an economics approach, including what she called resource heterogeneity creates Ricardian or monopoly rents. Ex Post limits to competition prevent the rents from being competed away. Imperfect Mobility ensures that valuable factors remain with the firm and that the rents are shared. Ex Ante Limits to competition keep costs from offsetting the rents. She further argued that these conditions are in fact related and said that firm profitability cannot be ascribed to differences in industry conditions, and furthermore all strategic implications depend on a firm's specific resource endowment. We can infer that her arguments are indeed to firm's internal and more passive factors dominate, while strategies should be more aggressive even when we look "silent", but actually waiting for the right moment to release counter moves.

\section{Discussion}

There is indeed no definite blueprint or prescription that can assure best possible profitability to all companies. However, companies need firm guidance and applicable tool(s) to stay on top of the business environments enabling them to survive and lead the industry through any turbulence. If there is no such "certainty", companies will not be able to strategically plan their resources and no strategic actions can be applied. The question of what to plan appears. From the three aforementioned fundamental concepts in strategic management we should now focus on which one is actually giving companies real options to plan and align their strategic activities, build relevant capabilities and resources, and therefore enable them to invest from now for 
future sustainable profit and competitive advantage. This is the essence of strategic management as necessary tool, not just a concept or theory per se.

\section{Conclusion}

Following the above, author recommends deeper research on company performances which follows the ESO-based or Environmentally-Driven concepts (beside AT\&T, Hewlet Packard, and Apple). It should be conducted at many companies of many industries and in different geographical countries to further verify the "Contingent Strategic Success Formula" (CSSF), as well as the Dynamic- Capabilities-based and Resource-based concepts. It is not the writer's purpose, however, to judge and declare which one of the three concepts is better and gives the most strategic success formula to companies because all concepts have their own strengths and weaknesses. Industry players need to prepare and anticipate all levels of turbulence by preparing proper and viable strategic planning along with explicit aggressive strategies as well as relevant capabilities to execute.

Given the current "digital" economy and in the near future more Environmental Turbulence, using and adding the ESO-based concept and the other two concepts, author would like to extend another level of environmental turbulence called "Deteriorating" at level six. The argument is that many companies are facing the sixth level of turbulence as a logical cause of market shrinkage, fast changes, and more intense competition. Companies will naturally and implicitly "strike back" at the established multinational companies. Deteriorating environmental turbulence at level six focuses on change as the stable variable which hypothetically will affect a company's performance. A company must prepare its strategic aggressiveness with dynamic technologies enhancement and general management capability responsiveness by preparing unique resources from level one to level six. This is the first paper which explicitly suggests an extension of Ansoff's Environment-Serving- Organization-based concept and therefore his Contingent Strategic Success Formula (CSSF) needs to be extended too (Table 3).

\section{Conflict of Interest}

The author has no conflict of interest to declare.

\section{References}

[1] Ansoff, H. I. (1958). A Model for Diversification Management Science 4 : 392-414 
TABLE 3: The Extension of matching turbulence, aggressiveness and responsiveness (Ansoff and Sullivan, 1993).
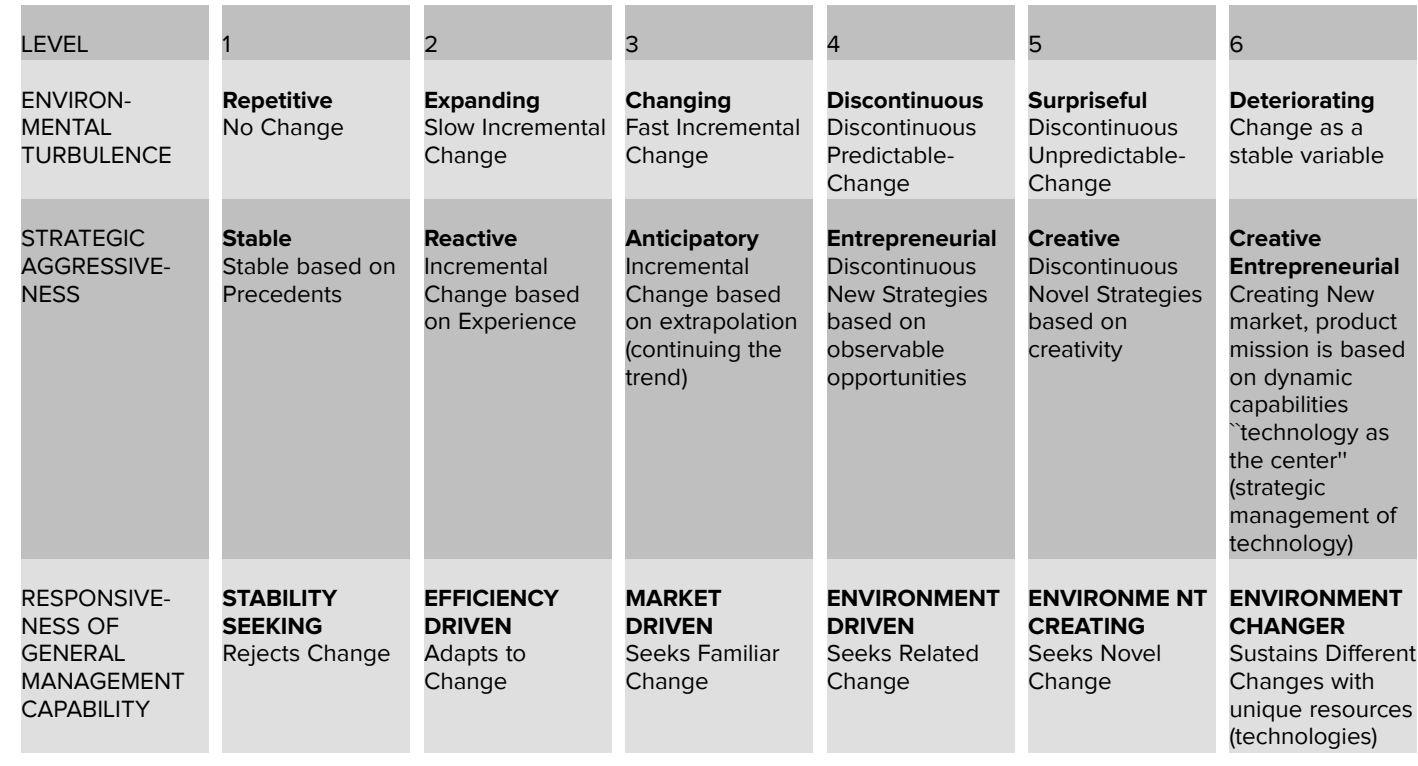

[2] Ansoff, H. I., Avner, J., Brandenburg, R. G., Portner, F. E., Radosevich, R. (1970). Does Planning Pay? The Effect of Planning on Success of Acquisitions in American Firms, Long Range Planning.

[3] Ansoff, H. I. (1977). Strategy Formulation As A Learning Process: An Applied Managerial Theory of Strategic Behavior International Studies of Management \& Organization Vol. 7, No. 2, pp. 58-77, (Published by: M.E. Sharpe, Inc.)

[4] Ansoff, H. I. (1987). Strategic Management of Technology Journal of Business Strategy, Vol. 7 Iss 3 pp. 28 - 39

[5] Ansoff, H. I. (1988). The New Corporate Strategy (John Wiley \& Sons, Inc., New York. Published originally as Corporate Strategy, New York: McGraw-Hill, 1965)

[6] Ansoff, H. I. and Mc Donnell, E. (1990). Implanting Strategic Management, 2nd Edition (Prentice Hall International, Cambridge, U.K.)

[7] Ansoff, H. I. and Sullivan, P. A. (1993). Optimizing Profitability in Turbulent Environments: A Formula for Strategic Success Long Range Planning Vol 26, N0. 5 , pp. 11 to 23

[8] Barney, J.B. (1991). Firm Resources and Sustained Competitive Advantage, Journal of Management 17, No. 1, 99-120

[9] Barney, J.B. (2001). Is The Resource-Based "View" A Useful Perspective For Strategic Management Research? Yes Academy of Management Review Vol. 26, No. 1, 41-56

[10] Djohar, S. (1991). The Relationships Between Strategic Effectiveness, Competitive Efficiency and Performance in Indonesian Firms an unpublished dissertation at 
the Graduate Faculty of the School of Business and Management, United States International University, San Diego, California, U.S.A.

[11] Eisenhardt K.M., Martin J.A. (2000). Dynamic Capabilities: What Are They? Strategic Management Journal, Vol. 21, No 10/11, Special Issue: The Evolution of Firm Capabilities, pp. 1105- 1121

[12] Freidank, J. (1994). Managing Transformational Change in German Business Firms an unpublished dissertation at the Graduate Faculty of the School of Business and Management (United States International University, San Diego, California, U.S.A.)

[13] Han, Y. W. (1999). The Relationships Between Environmental Turbulence, Top Manager Mindset, Organization Culture, Power and Performance in Korean Firms an unpublished dissertation at the Graduate Faculty of the College of Business Administration (United States International University, San Diego, California, U.S.A.)

[14] Hughes M., Martin S. L., Morgan R. E., and Robson, M. J. (2010). Realizing ProductMarket Advantage in High-Technology International New Ventures: The Mediating Role of Ambidextrous Innovation Journal of International Marketing (American Marketing Association) Vol. 18, No. 4, pp. 1--21

[15] Hughes, P., and Morgan, R. E. (2008). Fitting strategic resources with product-market strategy: Performance implications Journal of Business Research 6, 323--331

[16] Hussain S., Khattak, J., Rizwan, A., and Latif M. A. (2013) Ansoff Matrix, Environment, and Growth -- An Interactive Triangle Management and Administrative Sciences Review ISSN: 2308-1368 Volume: 2, Issue: 2, Pages: 196-206

[17] Kerin, R. A., and Peterson, R. A. (2013). Strategic Marketing Problems, Cases and Comments $\left(13^{\text {th }}\right.$ Ed.) New Jersey: Pearson Education Limited

[18] Mintzberg, H., Ahlstrand B., Lampel J. (1998). Strategy Safary, The Complete Guide Through The Wilds Of Strategic Management, Prentice Hall, London.

[19] Moussetis, R. C., Rahma, A. A., and Nakos, G. (2005). Strategic Behavior and national culture: the case of the banking industry in Jordan", competitiveness Review, International Business Journal, Vol. 15, Iss 2 pp. 101 - 115

[20] Oroh. A. N. (2016). Does Synergy Mentality Mediate between Strategic Planning Relationship and a Firm's Performance? An Empirical Study of Manufacturing Companies in Indonesia Pertanika J. Soc. Sci. \& Hum. 24 (S): 125 -- 138, ISSN: 0128-7702 (c) Universiti Putra Malaysia Press

[21] Oroh, A. N. (2018). Does Environment-Serving-Organisation Concept Affect Firm Performance? A Strategic Perspective Pertanika J. Soc. Sci. \& Hum. 26 (T): 239 -- 252, ISSN: 0128-7702 (c) Universiti Putra Malaysia Press 
[22] Peteraf, M. A. (1993). The Cornerstones of Competitive Advantage: A Resource-Based View Strategic Management Journal, Vol. 14, 179 -- 191 (John Wiley \& Sons, Ltd.)

[23] Peteraf, M. A., and Barney, J. B. (2003). Unraveling The Resource-Based Tangle Managerial and Decision Economics 24, pp 309 -- 323, (John Wiley \& Sons, Ltd.)

[24] Porter, M. E. (1983). Industrial Organization and The Evolution of Concepts for Strategic Planning: The New Learning, Managerial and Decision Economics, Vol. 4 No 3, Corporate Strategy

[25] Porter, M. E. (1985) Competitive Advantage, Creating and Sustaining Superior Performance, The Free Press, New York.

[26] Porter, M. E. (1996). What Is Strategy, Harvard Business Review, Reprint 96608, by the President and Fellows of Harvard College

[27] Priem, R.L., and Butler, J.E. (2001). Is the Resource-Based "View" a Useful Perspective for Strategic Management Research? Author(s): Richard L. Priem and John E. Butler Source: The Academy of Management Review, Vol. 26, No. 1, pp. 22-40 Published by: Academy of Management

[28] Rivkin, J. W. (2006). An Options-led Approach to Making Strategic Choices Harvard Business School, 9-702-433, (President and Fellows of Harvard College)

[29] Shanley, M., and Peteraf, M. (2004). Deploying, Leveraging, and Accessing Resources Within and Across Firm Boundaries: Introduction to the Special Issue Managerial and Decision Economics, 25, 291-297

[30] Teece, D.J., Pisano, G., Shuen, A. (1997). Dynamic Capabilities and Strategic Management, Strategic Management Journal, Vo. 18:7, 509-533, John Wiley \& Sons, Ltd.

[31] Vorhies, D. W., Morgan, R. E., and Autry, C. W. (2009). Product-Market Strategy and The Marketing Capabilities of The Firm: Impact on market effectiveness and cash flow performance Strategic Management Journal, 30, 1310-1334

[32] Wainaina, N. G., and Oloko, M. (2016). Market Penetration Strategies and Organizational Growth: A Case of Soft Drink Sector in Kenya International Journal of Management and Commerce Innovations ISSN 2348-7585 (Online) Vol. 3, Issue 2, pp: (219-227)

[33] Wernerfelt, B. (1984). A Resource-Based View of the Firm, Strategic Management Journal, Vol. 5, No. 2, pp. 171-180

[34] Wernerfelt, B. (1995). The Resource-Based View Of The Firm: Ten Years Later, Strategic Management Journal, Vol. 16 No.3, 171-174

[35] Yum, J. (2000). The Relationships Among Environmental Turbulence, Strategic Aggressiveness of Information Technology, Organizational Information Technology 
Capability, and Organizational Performance an unpublished dissertation at the Graduate Faculty of the College of Business Administration (United States International University, San Diego, California, U.S.A.)

[36] Zoysa, A. D., and Herath, S. K. (2007). The Impact of Owner/Managers' Mentality on Financial Performance of SMEs in Japan: An empirical investigation Journal of Management Development, Vol. 26 No. 7, pp. 652-666, Emerald Group Publishing Limited. 